\title{
Successful early application
}

Korean Journal of Anesthesiology

of extracorporeal membrane

oxygenation to support

cardiopulmonary resuscitation

for a patient suffering from severe

malignant hyperthermia and

cardiac arrest

-a case report-

\author{
Hyub Huh ${ }^{1}$, Jae Seung Jung ${ }^{2}$, Sang Jae Park ${ }^{1}$, Min Kyung Park ${ }^{1}$, \\ Choon Hak Lim ${ }^{1}$, and Seung Zhoo Yoon ${ }^{1}$ \\ Departments of ${ }^{1}$ Anesthesiology and Pain Medicine, ${ }^{2}$ Thoracic and Cardiovascular Surgery, Korea University \\ College of Medicine, Seoul, Korea
}

\begin{abstract}
Malignant hyperthermia (MH) may lead to metabolic crisis of skeletal muscle in susceptible individuals following exposure to triggering agents such as volatile anesthetics or depolarizing muscle relaxants. $\mathrm{MH}$ is a rare and a potentially lethal disease, which can lead to cardiac arrest. We report a case of severe $\mathrm{MH}$, in which the rapidly evolving signs of hypermetabolism eventually resulted in cardiac arrest. Despite conventional treatments following cardiopulmonary resuscitation, the patient's vital signs did not improve. Therefore, we applied extracorporeal membrane oxygenation for providing hemodynamic support.
\end{abstract}

Key Words: Dantrolene, Desflurane, Extracorporeal membrane oxygenation, Malignant hyperthermia.

Malignant hyperthermia ( $\mathrm{MH})$, an anesthetic-related autosomal dominant disorder of skeletal muscle calcium regulation,

Corresponding author: Seung Zhoo Yoon, M.D., Ph.D.

Department of Anesthesiology and Pain Medicine, Korea University Anam Hospital, 73, Inchon-ro, Seongbuk-gu, Seoul 02841, Korea

Tel: 82-2-920-5632, Fax: 82-2-929-2936

Email: yoonsz70@gmail.com

ORCID: http://orcid.org/0000-0002-9816-3531

Received: July 21, 2016.

Revised: November 21, 2016 (1st); December 8, 2016 (2nd).

Accepted: December 12, 2016.

Korean J Anesthesiol 2017 June 70(3): 345-349

https://doi.org/10.4097/kjae.2017.70.3.345 first characterized in 1962 [1], is triggered by succinylcholine and volatile anesthetics [2]. Once $\mathrm{MH}$ is triggered, an abnormally high release of calcium from the sarcoplasmic reticulum is initiated, which results in a hypermetabolic state with signs such as hemodynamic instability, tachycardia, muscle rigidity, hypercapnia, hyperthermia, hypoxia, rhabdomyolysis and lactic acidosis [3,4].

Dantrolene sodium is a specific antagonist of the pathophysiologic changes initiated by $\mathrm{MH}$ and is a life-saving drug when administered in the earlier stages [5]. After the introduction of dantrolene sodium, a causative treatment became available [6], and the mortality rate for acute $\mathrm{MH}$ crisis decreased from approximately $70-80 \%$ to about $5 \%$ [7]. Also, due to the decreased use of succinylcholine and the increased use of modern volatile

(c) This is an open-access article distributed under the terms of the Creative Commons Attribution Non-Commercial License (http://creativecommons.org/ licenses/by-nc/4.0/), which permits unrestricted non-commercial use, distribution, and reproduction in any medium, provided the original work is properly cited. 
anesthetics (sevoflurane, desflurane), the face of $\mathrm{MH}$ is changing from fulminant to more insidious [4]. Nevertheless, $\mathrm{MH}$ can still be a life-threatening disease which causes cardiac arrest, especially since sudden cardiac arrest still has a low survival rate, despite the introduction of cardiopulmonary resuscitation (CPR) [8].

We report a case of severe $\mathrm{MH}$, in which the rapidly evolving signs of hypermetabolism eventually resulted in cardiac arrest. Despite conventional treatments following CPR, the patient's vital signs did not improve. Therefore, we applied extracorporeal membrane oxygenation (ECMO) for providing hemodynamic support.

\section{Case Report}

A 56-year-old man (height $162.3 \mathrm{~cm}$, body weight $58.8 \mathrm{~kg}$ ) presented for emergency surgery of transurethral resection for bladder tumor due to bleeding associated with bladder cancer. His medical history included hypertension, stage IV chronic kidney disease and benign prostatic hypertrophy. There was no family history of $\mathrm{MH}$, and he had not been anesthetized previously.

Preoperatively, the patient had recurrent hematuria and a laboratory test revealed a hemoglobin $(\mathrm{Hb})$ concentration of $4.2 \mathrm{~g} / \mathrm{dl}$. The patient received transfusion of 2 pints packed red blood cells, and the $\mathrm{Hb}$ concentration increased to $6.8 \mathrm{~g} / \mathrm{dl}$. Gly- copyrrolate $0.2 \mathrm{mg}$ was injected intramuscularly as a premedication. In the operating room, an electrocardiogram, non-invasive blood pressure measurement, and pulse oximetry were performed, and the bispectral index (BIS VISTA ${ }^{\circledR}$, Aspect Medical Systems, Inc., Norwood, MA, USA) sensor was attached onto his forehead. The patient was preoxygenated for 2 minutes, and anesthesia was induced using $120 \mathrm{mg}$ of $1 \%$ propofol and $12 \mathrm{mg}$ cisatracurium. After intubation, anesthesia was maintained using desflurane in a total fresh gas flow of $3 \mathrm{~L} / \mathrm{min}$ of an air/oxygen mixture via an active humidified circuit with a heated wire in the inspiratory limb. In addition, effect-site target-controlled infusion of remifentanil was adjusted between 2.5 and $4.0 \mathrm{ng} /$ $\mathrm{ml}$. After consultation with the surgeon for considering the possibility of a radical cystectomy, catheters were placed in the right radial artery and right internal jugular vein as a precaution.

Baseline measurements at onset of surgery were oxygen saturation $\left(\mathrm{SpO}_{2}\right) 99 \%$, arterial blood pressure (ABP) 115/50 $\mathrm{mmHg}$, heart rate $(\mathrm{HR}) 90 \mathrm{bpm}$, end-tidal $\mathrm{CO}_{2}\left(\mathrm{ETCO}_{2}\right) 37 \mathrm{mmHg}$, and esophageal temperature $36.5^{\circ} \mathrm{C}$. Approximately 120 minutes after anesthesia induction, ABP was not checked. On inspection, right arm rigidity and lower extremity rigidity were detected. Then cannulation of the right brachial artery was performed. At that time, his ABP dropped to $95 / 45 \mathrm{mmHg}$ and $\mathrm{ETCO}_{2}$ rose to $54 \mathrm{mmHg}$. Repeated bolus injections of phenylephrine had a short duration, and hence a continuous infusion of norepinephrine was administered $(0.05 \mu \mathrm{g} / \mathrm{kg} / \mathrm{min})$. The esophageal tem-

Table 1. The Change in Vital Signs, $\mathrm{PetCO}_{2}, \mathrm{ABGA}$, Metabolic Parameters and Events

\begin{tabular}{|c|c|c|c|c|c|c|c|c|c|c|}
\hline & & \multicolumn{5}{|c|}{ Time after induction (h' min") } & \multirow{2}{*}{ POD \# 1} & \multirow{2}{*}{ POD \#3 } & \multirow{2}{*}{ POD \#7 } & \multirow{2}{*}{$\begin{array}{l}\text { POD \# } 10 \\
\text { POD \#2* }\end{array}$} \\
\hline & & $15^{\prime \prime}$ & 2'05" & 3' $05^{\prime \prime}$ & $4^{\prime} 25^{\prime \prime}$ & 6' 15" & & & & \\
\hline \multicolumn{2}{|c|}{$\mathrm{ABP}(\mathrm{mmHg})$} & $115 / 50$ & $95 / 45$ & $42 / 23$ & $51 / 28$ & $81 / 46$ & $90 / 46$ & $115 / 73$ & $157 / 70$ & $131 / 68$ \\
\hline \multicolumn{2}{|c|}{ HR (beats/min) } & 90 & 87 & 123 & 121 & 108 & 90 & 64 & 91 & 75 \\
\hline \multicolumn{2}{|c|}{ Body temperature $\left({ }^{\circ} \mathrm{C}\right)$} & 36.5 & 36.8 & 41.7 & 38.5 & 37.8 & 36.5 & 36.3 & 38.1 & 37.1 \\
\hline \multicolumn{2}{|c|}{$\mathrm{ETCO}_{2}(\mathrm{mmHg})$} & 37 & 54 & 80 & 32 & 25 & 28 & 34 & & 37 \\
\hline \multirow[t]{5}{*}{ ABGA } & $\mathrm{pH}$ & & 7.032 & 7.039 & 7.032 & 7.454 & 7.406 & 7.366 & & 7.364 \\
\hline & $\mathrm{PaCO}_{2}(\mathrm{mmHg})$ & & 73.1 & 90.9 & 27.4 & 17 & 31.8 & 42.2 & & 34.7 \\
\hline & $\mathrm{PaO}_{2}(\mathrm{mmHg})$ & & 108.8 & 150.8 & 154 & 437.3 & 113.6 & 118.7 & & 78.1 \\
\hline & $\mathrm{HCO}_{3}^{-}(\mathrm{mmol} / \mathrm{L})$ & & 19.6 & 24.7 & 10.3 & 12.3 & 20.2 & 24.4 & & 20 \\
\hline & Base excess & & -10.8 & -6.2 & -18.3 & -11.8 & -3.3 & -0.3 & & -4.2 \\
\hline \multirow[t]{2}{*}{ Electrolyte } & Sodium $(\mathrm{mmol} / \mathrm{L})$ & & & 143 & 142 & & 145 & 143 & 137 & 137 \\
\hline & Potassium $(\mathrm{mmol} / \mathrm{L})$ & & & 7.4 & 6.9 & & 4.7 & 4.3 & 3.5 & 3.4 \\
\hline \multicolumn{2}{|c|}{ BUN/Creatinine $(\mathrm{mg} / \mathrm{dl})$} & & & & & & $29.9 / 2.93$ & $23.0 / 2.11$ & $30.1 / 2.39$ & $41.3 / 2.21$ \\
\hline \multicolumn{2}{|c|}{ AST/ALT (IU/L) } & & & & & & $136 / 42$ & $644 / 183$ & $467 / 495$ & $83 / 176$ \\
\hline \multicolumn{2}{|c|}{ Serum creatine kinase (IU/L) } & & & 2413 & & & 17779 & & 9020 & 969 \\
\hline \multicolumn{2}{|c|}{ Serum myoglobin (ng/ml) } & & & 145.2 & & & 5072 & & & \\
\hline \multicolumn{2}{|c|}{ Troponin I (ng/ml) } & & & 0.308 & & & & & & \\
\hline \multicolumn{2}{|c|}{ Events } & & + & ${ }^{\ddagger}$ & $\S$ & $"$ & & ฯ & & $* *$ \\
\hline
\end{tabular}

$\mathrm{ETCO}_{2}$ : end-tidal carbon dioxide, ABGA: arterial blood gas analysis, ABP: arterial blood pressure, HR: heart rate, BUN: blood urea nitrogen, AST: aspartate transaminase, ALT: alanine transaminase. ${ }^{*} \mathrm{POD} \# 2$ : post-operative day 2, after the second operation, ${ }^{\dagger}$ Muscle rigidities and increasing minute volume, ${ }^{\dagger}$ Before dantrolene sodium administration, ${ }^{\S}$ After dantrolene sodium administration and cardiac arrest, "After application of extracorporeal membrane oxygenation (ECMO; $\mathrm{FiO}_{2}$ 0.6, Flow $3.3 \mathrm{~L} / \mathrm{min}$ [ECMO, $\mathrm{FIO}_{2}$ 0.6, flowrate $\left.3.3 \mathrm{~L} / \mathrm{min}\right]$ ), ${ }^{\mathbb{I}} \mathrm{After}$ weaning off the ECMO, **After radical cystectomy with an ileal-conduit. 
perature was maintained at $36.2^{\circ} \mathrm{C}$. We proceeded with manual hyperventilation to increase minute ventilation (MV) from 6.2 to $8.4 \mathrm{~L} / \mathrm{min}$; however, $\mathrm{ETCO}_{2}$ remained above $60 \mathrm{mmHg}$. Bilateral breath sounds were clear without wheezing and the peak airway pressure remained unchanged. At this point, arterial blood gas analysis (ABGA) showed $\mathrm{pH}$ 7.032, $\mathrm{PaO}_{2} 108.1$ $\mathrm{mmHg}, \mathrm{PaCO}_{2} 73.1 \mathrm{mmHg}$ and base excess $(\mathrm{BE})-10.8 \mathrm{mmol} / \mathrm{L}$. (Table 1). Therefore, we administered sodium bicarbonate 60 $\mathrm{mEq}$. The esophageal temperature increased gradually to $38.6^{\circ} \mathrm{C}$. The clinical condition of the patient was suspected to be due to $\mathrm{MH}$, and hence the operation was stopped and dantrolene sodium was prepared. One hundred and fifty minutes after induction of anesthesia, hypotension still persisted and the HR gradually rose to $120 \mathrm{bpm}$. Next, a continuous vasopressin infusion was initiated and both the breathing circuit and soda lime canister were changed. In spite of increasing MV to $14.5 \mathrm{~L} / \mathrm{min}$, the retention of $\mathrm{CO}_{2}$ intensified, and so the ventilator was replaced. In addition, desflurane was discontinued and it was washed out with $100 \% \mathrm{O}_{2}$ in $18 \mathrm{~L} / \mathrm{min}$ fresh gas over a period of 10 minutes. At the same time, anesthesia was switched to $2 \%$ propofol (Fresofol $2 \%{ }^{\mathrm{TM}}$, Fresenius Kabi, Granz, Austria) and the ventilator was replaced with continuous manual hyperventilation. To cool off the patient, ice packs were placed on the head and chest areas and cold saline irrigation was administered through the Foley catheter and the Levin tube. The $\mathrm{ETCO}_{2}$ rose to more than 80 mmHg and the $\mathrm{SpO}_{2}$ gradually decreased to $94 \%$. At this point, the esophageal temperature was $41.7^{\circ} \mathrm{C}$ and $\mathrm{ABGA}$ showed $\mathrm{pH}$ 7.039, $\mathrm{PaO}_{2} 150.8 \mathrm{mmHg}, \mathrm{PaCO}_{2} 90.9 \mathrm{mmHg}$ and $\mathrm{BE}-6.2$ $\mathrm{mmol} / \mathrm{L}$. Also, serum potassium and lactic acid levels were 7.37 $\mathrm{mmol} / \mathrm{L}$ and $11.7 \mathrm{mmol} / \mathrm{L}$, respectively. We administered $10 \mathrm{mg}$ furosemide and a regular insulin infusion (10 IU/h). Despite administration of norepinephrine and vasopressin, his ABP dropped rapidly to $42 / 23 \mathrm{mmHg}$. Epinephrine 100 and $300 \mu \mathrm{g}$ was then injected intravenously in a sequence. Dantrolene sodium arrived in the operating room and it was reconstituted with sterile water as quickly as possible and administered through the central venous line. The esophageal temperature at this point was $40.5^{\circ} \mathrm{C}$, but within the first $1-2$ minutes following $60 \mathrm{mg}$ dantrolene sodium, a rapid decrease in the esophageal temperature to $38.5^{\circ} \mathrm{C}$ and a drop in $\mathrm{ETCO}_{2}$ to $32 \mathrm{mmHg}$ were noted. However, at this time, the patient suffered a cardiac arrest with asystole. Then, the infusion of dantrolene sodium was stopped and CPR was initiated immediately following chest compression and epinephrine injection. After 15 seconds of CPR, ventricular fibrillation occurred and the patient's cardiac rhythm converted back to sinus rhythm after a single defibrillation at $200 \mathrm{~J}$. Boluses of epinephrine $1 \mathrm{mg}$ were injected 3 times. Despite infusion of epinephrine and vasopressin, the patient's ABP did not improve. We made a decision to initiate ECMO for providing hemodynamic support and activated an ECMO team. Peripheral veno- arterial ECMO was applied by using a size of 15 French (F) arterial cannula (Biomedicus ${ }^{\circledR}$, Medtronic, Anaheim, CA, USA) and a size of $21 \mathrm{~F}$ venous cannula (Biomedicus ${ }^{\circledR}$, Medtronic, Anaheim, CA, USA) into the right femoral artery and vein, respectively. The initial blood flow rate was $3.5 \mathrm{~L} / \mathrm{min}$ and the sweep gas-flow rate was $3.0 \mathrm{~L} / \mathrm{min}$. The total down time for the first cardiac arrest was 80 minutes until ECMO was ready. After applying ECMO, the patient's ABP improved. The patient was then transferred to the surgical intensive care unit (SICU) running an ECMO. No more dantrolene sodium was administered, because the rigidity of the right arm and the lower extremity had resolved, and $\mathrm{ETCO}_{2}$, body temperature and ABGA had improved before the patient was transferred to the SICU. The serum creatine kinase (CK) levels were elevated upon admission (CK 2,413 IU/L) and they continued to be elevated till the following morning (CK 17,779 IU/L). MH clinical grading scale score was 73 (MH rank was 6, 'Almost certain'). Sixty hours later, the patient was successfully weaned off ECMO. A week later, he was inevitably scheduled for a radical cystectomy with an ilealconduit due to the remnant bladder tumor, persistent hematuria in spite of arterial embolization and bladder necrosis. For general anesthesia, we performed total intravenous anesthesia using $2 \%$ propofol. The patient's vital signs were stable during the operation and the operation was completed uneventfully. After one week, the patient displayed a hemodynamically stable state, was extubated, and then transferred to the general ward.

\section{Discussion}

To our knowledge, early application of ECMO in severe cases of $\mathrm{MH}$ accompanied by cardiac arrest in spite of immediate treatment with dantrolene sodium has not yet been reported. It is important that the prognosis of $\mathrm{MH}$ crisis depends on how soon $\mathrm{MH}$ is suspected and how rapidly an appropriate treatment is initiated; because the $\mathrm{MH}$ crisis including rigidity, muscle breakdown, cardiac involvement and metabolic derangement, is aggravated as time passes. However recently, the clinical manifestation of $\mathrm{MH}$ tended to have an insidious and delayed onset rather than a fulminant onset [4]. Therefore, the monitoring of raising $\mathrm{ETCO}_{2}$, an early sign of $\mathrm{MH}$ in the perioperative period, is important for early administration of dantrolene sodium. Administration of triggering agents must be stopped immediately and anesthesia should be continued using intravenous opioids, sedatives, and, if necessary, non-depolarizing muscle relaxants. The vaporizer used for administration of volatile anesthesia should be removed from the anesthesia machine and the patient should be hyperventilated with $100 \%$ oxygen at a maximum fresh gas flow, increasing the minute volume by approximately 2-3 fold, while aiming for an $\mathrm{ETCO}_{2}$ within the normal limits [3]. The gold standard for diagnosis of $\mathrm{MH}$ susceptibility is the caf- 
feine-halothane contracture test [5]. But DNA analysis, requiring only a blood sample, could be an alternative to this invasive test [7]. However, as this test is not widely available, the diagnosis of $\mathrm{MH}$ can be made by clinical presentation in most cases [5]. Therefore, we diagnosed $\mathrm{MH}$ based on clinical symptoms and the clinical symptom ceased on dantrolene administration.

In our case, administration of dantrolene sodium was stopped following $60 \mathrm{mg}$ infusion. Dantrolene sodium has been known to block the Ryanodine receptors (RyRs), and it acts directly on RyR1 and RyR3 isoforms, reduces the channel activation by calmodulin, and reduces the channel sensitivity to $\mathrm{Ca}^{2+}[9]$. Notably dantrolene sodium does not have a negative inotropic effect on the heart because it does not block RyR2, the cardiac RyRs [9]. However, several studies have suggested that dantrolene sodium might inhibit $\mathrm{Ca}^{2+}$ release via both $\mathrm{RyR} 1$ and RyR2, and it can affect cardiac function under pathophysiologic conditions $[10,11]$. Due to the possibility of worsening cardiac function in a hemodynamically unstable condition, we stopped the infusion of dantrolene sodium.

ECMO, as a device for cardiac resuscitation, was proposed in the early 1960s, and it has shown encouraging outcomes in patients with cardiac arrest [8]. In addition, ECMO is a therapeutic option increasingly used in the management of patients with refractory cardiorespiratory failure [12]. Advances in technology have allowed such a treatment to be deployed more rapidly, and several descriptive series investigations have shown encouraging outcomes in patients with cardiac arrest [8]. This gradual increase in the use of ECMO has also been described in the the Extracorporeal Life Support Organization (ELSO) registry [13]. According to these data, patients with myocarditis and cardiomyopathy benefit more from an ECMO treatment than patients with congenital defects or those who are in cardiogenic shock [13]. In their 2005 CPR guidelines, the American Heart Association recommended the use of ECMO at institutions capable of deploying it rapidly in patients who had an in-hospital cardiac arrest, received good-quality CPR, and were thought to have a reversible cause of their cardiac arrest [14]. Despite the absence of controlled trials, there is principal support for the use of ECMO in the case of CPR in the AHA/ACC guidelines for advanced cardiac life support [15].

In cases of malignant hyperthermia accompanied by cardiac arrest in spite of immediate treatment with dantrolene sodium, early application of ECMO for providing cardiopulmonary support should be considered as a promising therapeutic option in order to improve the probability of patient survival when conventional cardiac arrest management has failed.

\section{ORCID}

Hyub Huh, http://orcid.org/0000-0002-2321-1148

Jae Seung Jung, http://orcid.org/0000-0002-8848-4112

Choon Hak Lim, http://orcid.org/0000-0003-0089-7682

Seung Zhoo Yoon, http://orcid.org/0000-0002-9816-3531

\section{References}

1. Denborough MA, Forster JF, Lovell RR, Maplestone PA, Villiers JD. Anaesthetic deaths in a family. Br J Anaesth 1962; 34 : 395-6.

2. Levitt RC. Prospects for the diagnosis of malignant hyperthermia susceptibility using molecular genetic approaches. Anesthesiology 1992; 76: $1039-48$.

3. Schneiderbanger D, Johannsen S, Roewer N, Schuster F. Management of malignant hyperthermia: diagnosis and treatment. Ther Clin Risk Manag 2014; 10: 355-62.

4. Heytens L, Forget P, Scholtès JL, Veyckemans F. The changing face of malignant hyperthermia: less fulminant, more insidious. Anaesth Intensive Care 2015; 43: 506-11.

5. Turhan KS, Baytaş V, Batislam Y, Ozatamer O. Delayed onset malignant hyperthermia after sevoflurane. Case Rep Anesthesiol 2013; 2013: 712710.

6. Harrison GG. Control of the malignant hyperpyrexic syndrome in MHS swine by dantrolene sodium. Br J Anaesth 1975; 47: 62-5.

7. Rosenberg H, Davis M, James D, Pollock N, Stowell K. Malignant hyperthermia. Orphanet J Rare Dis $2007 ; 2: 21$.

8. Chen YS, Lin JW, Yu HY, Ko WJ, Jerng JS, Chang WT, et al. Cardiopulmonary resuscitation with assisted extracorporeal life-support versus conventional cardiopulmonary resuscitation in adults with in-hospital cardiac arrest: an observational study and propensity analysis. Lancet 2008; 372: 554-61.

9. Correia AC, Silva PC, da Silva BA. Malignant hyperthermia: clinical and molecular aspects. Rev Bras Anestesiol 2012; 62: 820-37.

10. Oo YW, Gomez-Hurtado N, Walweel K, van Helden DF, Imtiaz MS, Knollmann BC, et al. Essential role of calmodulin in RyR inhibition by dantrolene. Mol Pharmacol 2015; 88: 57-63.

11. Kobayashi S, Yano M, Suetomi T, Ono M, Tateishi H, Mochizuki M, et al. Dantrolene, a therapeutic agent for malignant hyperthermia, markedly improves the function of failing cardiomyocytes by stabilizing interdomain interactions within the ryanodine receptor. J Am Coll Cardiol 2009; 53: 1993-2005.

12. MacLaren G, Combes A, Bartlett RH. Contemporary extracorporeal membrane oxygenation for adult respiratory failure: life support in the 
new era. Intensive Care Med 2012; 38: 210-20.

13. Paden ML, Conrad SA, Rycus PT, Thiagarajan RR. Extracorporeal Life Support Organization Registry Report 2012. ASAIO J 2013; 59: 20210.

14. Thiagarajan RR. Extracorporeal membrane oxygenation to support cardiopulmonary resuscitation: Useful, but for whom? Crit Care Med 2011; 39: 190-1.

15. Morrow DA, Fang JC, Fintel DJ, Granger CB, Katz JN, Kushner FG, et al. Evolution of critical care cardiology: transformation of the cardiovascular intensive care unit and the emerging need for new medical staffing and training models: a scientific statement from the American Heart Association. Circulation 2012; 126: 1408-28. 